\title{
POSSIBILITIES OF A COMBINED BIOPHYSICAL NON-INVASIVE FETAL MONITORING DURING LABOUR IN REDUCING THE FREQUENCY OF OPERATIVE DELIVERIES - A RANDOMIZED STUDY
}

\author{
Dokus $\mathrm{K}^{1}$, Matasova $\mathrm{K}^{2}$, Visnovsky $\mathrm{J}^{1}$, Dokusova $\mathrm{S}^{3}$, Danko J. ${ }^{1}$ \\ ${ }^{1}$ Dept. of Obstetrics and Gynaecology and ${ }^{2}$ Dept. of Neonatology, Jessenius Faculty of Medicine, Comenius \\ University, Martin, Slovak Republic \\ ${ }^{3}$ National Endocrinology and Diabetology Institute, Lubochna, Slovakia
}

\begin{abstract}
A bstract
Objective. The aim of the study was to test the performance and safety of fetal pulse oximetry (FPO) in the management of non-reassuring CTG patterns in labour.

Materials. A randomized controlled trial was conducted in 648 women in active labour and pregnancies $>36$ weeks with reassuring admission CTG followed by non-reassuring patterns. All women were divided into 2 groups according to the mode of fetal intrapartum monitoring used. In the study group $(n=324)$, women received a combined biophysical fetal monitoring with CTG plus FPO $(n=324)$, while the control group of women had CTG alone monitoring. Main outcome measures were rates of operative deliveries and neonatal outcome.

Results. The analysis showed a significant reduction of Caesarean deliveries in the study group receiving a combined fetal monitoring compared to controls $(45 / 324$ vs. $67 / 324 ; \mathrm{P}=0.022)$. The total operative delivery rate was also lower, but not significantly (92/324 vs. 104/324, $\mathrm{P}=0.302)$. No comparative differences were observed in neonatal outcomes, except for 2 controls-group neonates born with pH-UA $<7.1$, however completely normal further postnatal course. No such case was encountered in the study group neonates, and no perinatal deaths occurred during the study.

Conclusions. A combined biophysical intrapartum fetal monitoring with CTG and fetal pulse oximetry enables safe reduction in Caesarean rate for non-reassuring CTG patterns, however it could not decrease a total operative delivery rate. Condensation: Fetal pulse oximetry safely reduces a Caesarean rate for non-reassuring patterns, but not the overall Caesarean rate.
\end{abstract}

Key words: cardiotocography, fetal pulse oximetry, non-reassuring CTG patterns, operative delivery

\section{INTRODUCTION}

At present, electronic fetal monitoring, also known as cardiotocography (CTG), is a wellestablished method of fetal surveillance in labour. It has brought in a significant reduction in intrapartum fetal deaths, yet this has been outbalanced with unnecessarily increased Caesarean rates due to its low specificity for detection of fetal hypoxia. Its completion with fetal scalp blood sampling (FBS) may reduce these rates, however, its invasive character and a need of repeated sampling substantially limited its current use [1].

In order to improve CTG specificity in detection of fetal hypoxia a non-invasive fetal pulse oximetry (FPO) was introduced and evaluated in observational studies [2]. The method was devised to continuously measure oxygen saturation (SpO2) of the fetal hemoglobin that should have at least two advantages: a) it can detect the primary variable underlying fetal hypoxia (SpO2), and b) it is based on a recognized technology used in intensive care units and operating theatres throughout the world $[3,4]$.

The aim of the present study was to test performance and safety of FPO in the management of non-reassuring CTG patterns in labour. Main outcome measures were rates of operative deliveries and neonatal outcome.

Address for corres pond e n c e:

Karol Dokus, MD, PhD, Kollarova 2, 03608 Martin, Slovakia

Tel/fax: 00421-43-4134185; e-mail: dokus@jfmed.uniba.sk 


\section{METHODS}

A randomized controlled trial was conducted at the Department of Obstetrics and Gynaecology of the Jessenius Faculty of Medicine in Martin, Slovak Republic. The faculty's Ethics committee gave approval to the study protocol.

The inclusion criteria were as follows: low risk singleton pregnancy $\geq 36$ weeks, cephalic presentation, and reassuring admission CTG followed by non-reassuring patterns in active labour. All women consented before randomization to 2 trial groups (study and control) according to the kind of fetal monitoring used. Women would have been excluded if there were preterminal CTG patterns (e.g. complete loss of variability with late decelerations or bradycardia) on randomization, or known genital herpes infection. A randomization method using the permuted - blocks model (size of 8) was chosen to reach equivalent numbers in both groups. Accordingly, randomization key and numbered opaque sealed envelopes were prepared outside the study personnel.

\section{Fetal monitoring and management of labours}

In both groups, CTG monitoring was accomplished with a CTG monitor series 50A (Agilent Technologies, USA), and patterns were assessed according to FIGO classification (1987). In case of non-reassuring patterns continuous CTG monitoring ensued with the use of ancillary techniques to elicit fetal reactivity, and to exclude fetal acidemia. These techniques included fetal scalp stimulation, lateral positioning of a woman, mask oxygen inhalation, and intravenous fluids in case of maternal hypotension (e.g. during epidural analgesia).

Except, in the study group, non-reassuring patterns indicated use of FPO as an adjunct to CTG. FPO was accomplished using Nellcor N-400 monitor with fetal sensor FS-14C (Nellcor Puritan Bennett, Pleasanton, USA) that was interfaced to a CTG monitor. $\mathrm{SpO}_{2}$ data were continuously registered to a CTG strip. Values of $\mathrm{SpO}_{2} \leq 30 \%$ for a period $\geq 10$ minutes, signalling fetal hypoxia, led to expedited delivery. With $\mathrm{SpO}_{2}>30 \%$ and non-reassuring patterns a labour could continue vaginally.

In the control group, the delivery was expedited if non-reassuring patterns persisted $\geq 45$ minutes. Generally, preterminal CTG patterns led to immediate delivery in both groups.

\section{Neonatal assessment}

Neonatal condition was assessed by an attending neonatologist with records on Apgar scores at 1, 5 and 10 minutes of life, arterial umbilical pH (pH-UA), and blood gases values. Signs of perinatal asphyxia (neonatal seizures, followed encephalopathy), neonatal sepsis, respiratory distress syndrome (RDS), and jaundice were sought for. Further, need of mask oxygen application, resuscitation, and transfer to neonatal intensive care unit (ICU) were observed.

\section{Statistical analysis}

Analysis of the study data was done using non-parametric Mann-Whitney U test, except for the proportions of types of deliveries tested with a ${ }^{2}$ test, based on Pearson's distribution. In order to assess diagnostic performance of FPO, ROC analysis was used. The level of statistical significance was assumed $\mathrm{P}=0.05$.

\section{RESULTS}

In total, 648 women were enrolled to the study and gave informed consent. The study and control groups comprised equally of 324 women. No significant differences in demographic data variables, number of labour inductions, epidural analgesia, duration of the labour stages or cervix dilatation on study entry were seen between the groups (Tab. 1). 
Table 1.Demographic data and labour characteristics in the study.

\begin{tabular}{|c|c|c|c|c|c|c|c|}
\hline & Control & Study & & & & & $\mathbf{P}$ \\
\hline & $(n=324)$ & $(\mathrm{n}=324)$ & Control & Study & Control & Study & \\
\hline Age (years; $x \pm S D$ ) & $28.9 \pm 5.3$ & $27.8 \pm 4.9$ & 18 & 18 & 45 & 39 & NS \\
\hline Parity $(\mathrm{a} ; \mathrm{x} \pm \mathrm{SD}$ ) & $0.5 \pm 1,1$ & $0,5 \pm 0.8$ & 0 & 0 & 7 & 3 & NS \\
\hline Previous Caesarean (n-\%) & $29-9.0$ & $26-8.0$ & - & - & - & - & NS \\
\hline Weeks of gestation $(x \pm S D)$ & $40.1 \pm 1.5$ & $40.3 \pm 1.0$ & 36 & 36 & 43 & 42 & NS \\
\hline Weight (kg; x土SD) & $74.3 \pm 9.0$ & $73.9 \pm 8.0$ & 58 & 59 & 96 & 105 & NS \\
\hline Height (cm; x \pm SD) & $170.4 \pm 5.5$ & $169.3 \pm 4.7$ & 156 & 157 & 183 & 181 & NS \\
\hline Labour induction (n-\%) & $74-23.0$ & $86-26.5$ & - & - & - & - & NS \\
\hline Epidural analgesia (n-\%) & $39-12.0$ & $49-15.1$ & - & - & - & - & NS \\
\hline $\begin{array}{l}\text { Cervical dilatation* } \\
\text { (cm; } \pm \text { } \pm \text { SD) }\end{array}$ & $5,3 \pm 1,1$ & $5,6 \pm 1,2$ & 2,0 & 2,0 & 8,0 & 8,0 & NS \\
\hline $1^{\text {st }}$ stage (min; $x \pm \mathrm{SD}$ ) & $466 \pm 260$ & $483 \pm 234$ & 140 & 120 & 1200 & 1065 & NS \\
\hline $2^{\text {nd }}$ stage $(\mathrm{min} ; \mathrm{x} \pm \mathrm{SD})$ & $15 \pm 13$ & $16 \pm 15$ & 3 & 5 & 73 & 88 & NS \\
\hline Birth weight ( $g ; x \pm S D$ ) & $3354 \pm 552$ & $3392 \pm 434$ & 1900 & 2030 & 4310 & 4330 & NS \\
\hline Low birth weight (n-\%) & $34-10.5$ & $36-11.1$ & - & - & - & - & NS \\
\hline $\begin{array}{l}\text { Birth weight }>4000 \mathrm{~g} \\
\text { (n-\%) }\end{array}$ & $13-4.0$ & $10-3.1$ & - & - & - & - & NS \\
\hline
\end{tabular}

Legend: * Cervical dilatation on study entry.

In the study group, we found the significantly fewer Caesarean sections indicated for fetal hypoxia $(\mathrm{P}=0.022)$, and lower, but not significant, their total frequency $(28.4 \% \mathrm{vs} .32 .1 \%$, $\mathrm{P}=0.347$ ). No other major differences were observed in indications, or modes of deliveries (Tab. 2).

Table 2 Mode of delivery and indication to obstetric operation.

\begin{tabular}{|c|c|c|c|}
\hline Delivery mode & $\begin{array}{c}\text { Control } \\
(\mathrm{n}-\%)\end{array}$ & $\begin{array}{c}\text { Study } \\
(\mathrm{n}-\%)\end{array}$ & $\mathrm{P}\left(\boldsymbol{\chi}^{2}\right)$ \\
\hline Vaginal & $207-63.9$ & $218-67.3$ & $\mathrm{NS}$ \\
\hline Forceps fetal hypoxia & $13-4.0$ & $14-4.3$ & $\mathrm{NS}$ \\
\hline other indications & $10-3.1$ & $12-3.7$ & $\mathrm{NS}$ \\
\hline Caesarean $\quad 3-0.9$ & $2-0.6$ & $\mathrm{NS}$ \\
\hline fetal hypoxia & $104-32.1$ & $92-28.4$ & $\mathrm{NS}$ \\
\hline labour dystocia & $67-20.7$ & $45-13.9$ & $\mathrm{NS}$ \\
\hline threat of uterine rupture & $26-8.0$ & $34-10.5$ & $\mathrm{NS}$ \\
\hline other indications & $9-2.8$ & $12-3.7$ & $\mathrm{NS}$ \\
\hline
\end{tabular}


As for neonatal outcome, no significant differences were encountered between the groups, except for 2 control cases with UA - $\mathrm{pH}<7.1$, but no such case in the study group. There were no neonatal deaths in the study (Tab. 3).

Table 3. Neonatal outcome in the study.

\begin{tabular}{|c|c|c|c|}
\hline Variable & $\begin{array}{l}\text { Control } \\
(n=324)\end{array}$ & $\begin{array}{c}\text { Study } \\
(n=324)\end{array}$ & $\begin{array}{c}\mathrm{P}\left(\chi^{2}\right) \\
\left({ }^{*} \mathrm{M}-\mathrm{W} \text { test }\right)\end{array}$ \\
\hline Apgar 1'< 4 (n-\%) & $4-1.2$ & $3-0.9$ & NS \\
\hline Apgar 5' < 7 (n-\%) & $5-1.5$ & $4-1.2$ & NS \\
\hline Apgar 1' $(\mathrm{x} \pm \mathrm{SD})^{*}$ & $8.0 \pm 1.6$ & $8.1 \pm 1.2$ & NS \\
\hline Apgar 5' $(\mathrm{x} \pm \mathrm{SD})^{*}$ & $8.7 \pm 1.4$ & $8.9 \pm 1.0$ & NS \\
\hline Apgar 10' $(\mathrm{x} \pm \mathrm{SD})^{*}$ & $9.2 \pm 1.1$ & $9.1 \pm 1.3$ & NS \\
\hline pH-UA $(\mathrm{x} \pm \mathrm{SD})^{*}$ & $7.31 \pm 0.11$ & $7.33 \pm 0.07$ & NS \\
\hline pH-UA $\leq 7.00$ (n-\%) & $1-0.3$ & $0-0$ & NS \\
\hline pH-UA $\leq 7.10(n-\%)$ & $2-0.6$ & $0-0$ & NS \\
\hline pH-UA $\leq 7.15$ (n-\%) & $6-1.9$ & $8-2.5$ & NS \\
\hline BE-UA (mmol/l; $\mathrm{x} \pm \mathrm{SD})^{*}$ & $-3.4 \pm 4.1$ & $-3.3 \pm 3.4$ & NS \\
\hline Mask oxygen (n-\%) & $53-16.3$ & $46-14.2$ & NS \\
\hline Intubation (n-\%) & $3-0.9$ & $1-0.3$ & NS \\
\hline Transfer to ICU (n-\%) & $7-2.2$ & $6-1.8$ & NS \\
\hline Encephalopathy (n-\%) & $1-0.3$ & $0-0$ & NS \\
\hline Seizures (n-\%) & $1-0.3$ & $0-0$ & NS \\
\hline Sepsis (n-\%) & $1-0.3$ & $0-0$ & NS \\
\hline IRDS (n-\%) & $0-0$ & $0-0$ & - \\
\hline Jaundice (n-\%) & $25-7.8$ & $31-9,5$ & NS \\
\hline
\end{tabular}

Legend: $\mathrm{NS}=$ not significant, $\mathrm{UA}=$ umbilical artery

Table 4. Comparison of proportions of non-reassuring CTG phenomena in the trial groups following randomization.

\begin{tabular}{|l|c|c|c|}
\hline CTG phenomena & $\begin{array}{c}\text { Control } \\
(\mathrm{n}-\%)\end{array}$ & $\begin{array}{c}\text { Study } \\
(\mathrm{n}-\%)\end{array}$ & $\mathrm{P}\left(\chi^{2}\right)$ \\
\hline $\begin{array}{l}\text { Uncomplicated variable dec. }(<60 \mathrm{bpm}) \\
\pm \text { variability }<5 \text { bpm }\end{array}$ & $186-57.4$ & $170-52.5$ & NS \\
\hline $\begin{array}{l}\text { Complicated variable dec. } \\
(>60 \text { bpm, }>60 \text { s) }\end{array}$ & $39-12.0$ & $34-10.5$ & NS \\
\hline Sporadic late dec. & $116-35.8$ & $123-38.0$ & NS \\
\hline Repeated late dec. $(>50 \%$ of contractions) & $13-4.0$ & $12-3.7$ & NS \\
\hline $\begin{array}{l}\text { Prolonged dec. } \\
(<80 \text { bpm and }>2 \text { min, }<100 \text { bpm and }>3 \text { min) }\end{array}$ & $8-2.5$ & $13-4.0$ & NS \\
\hline Silent variability $<5$ bpm $(>40$ min) & $34-10.5$ & $45-13.9$ & NS \\
\hline Periodic accelerations \pm variability $<5$ bpm & $22-6.8$ & $15-4.6$ & NS \\
\hline Baseline bradycardia $100-110$ bpm & $3-0.9$ & $2-0.6$ & NS \\
\hline Baseline tachycardia $>170$ bpm & $18-5.6$ & $21-6.5$ & NS \\
\hline
\end{tabular}

Legend $:$ NS = not significant, dec. $=$ deceleration 
In order to assess a possible difference in the degree of CTG pathology between the groups, we evaluated proportions of several different non-reassuring CTG phenomena on all non-reassuring CTG strips on study entry, and CTG patterns 30 minutes before deliveries. According to the FIGO classification we recognised 3 categories of the CTG patterns - reassuring, non-reassuring, and preterminal. No significant difference in CTG pathology was found between the groups (Tab. 4 and 5).

Table 5. Classification of CTG patterns 30 minutes before the deliveries.

\begin{tabular}{|l|c|c|c|}
\hline CTG category & $\begin{array}{c}\text { Control } \\
(\mathrm{n}=324) \\
(\mathrm{n}-\%)\end{array}$ & $\begin{array}{c}\text { Study } \\
(\mathrm{n}=324) \\
(\mathrm{n}-\%)\end{array}$ & $\mathbf{P}\left(\chi^{2}\right)$ \\
\hline Reassuring & $119-36.7$ & $123-38.0$ & 0.79 \\
\hline Non-reassuring & $203-62.7$ & $200-61.7$ & 0.86 \\
\hline Preterminal & $2-0.6$ & $1-0.3$ & 0.98 \\
\hline
\end{tabular}

\section{DISCUSSION}

The main benefit of FPO for obstetrical practice is seen in its presumed ability to reduce the unnecessarily high Caesarean rate due to non-reassuring patterns if SpO2 values are within normal range (>30\%). The labour could be then allowed to proceed vaginally despite non-reassuring CTG [5 - 7].

Similar ability of FPO was confirmed in the large U.S. randomized trial, but no such effect could be proved for the total operative delivery rate. The use of FPO also resulted in a significantly increased number of Caesareans due to labour dystocia that couldn't be satisfactorily explained, then. With SpO2 values > 30\%, however, the observed reduction in Caesarean deliveries for non-reassuring patterns had no adverse impact on neonatal outcome [8].

Despite a few reports on lower sensitivity of FPO for detection of fetal acidemia in labour [9 - 11], the ability of FPO to safely decrease unnecessary obstetric operations was then confirmed in a German multi-center study that used the critical SpO2 value of 30\%, too [2].

Likewise, a successive study by Kühnert and Schmidt on 146 women in active labour, suggested that triple monitoring with CTG plus FBS and FPO, compared to CTG plus FBS, might help to reduce the rate of obstetric surgery and the number of FBS samplings in a need [12].

Our results are in accordance with the findings of the above-mentioned multi-centre trials, thus bringing further evidence that CTG plus FPO surveillance could decrease the rate of Caesarean sections for non-reassuring CTG patterns. However, our data also prove no lowering effect on the overall obstetric surgery rate. We suppose that this insignificant overall decrease could be due to a relatively small size of the studied populations. Further, similarly to the U.S. trial [8], we observed a rise in Caesarean sections due to labour dystocia, though in our study this was not significant. Some clues to this phenomenon were probably given in a later study of Porreco et al. who showed that significantly non-reassuring patterns of a normally oxygenated fetus could predict Caesarean delivery for labour dystocia, and this might be explanatory for the observed "unbalanced" frequency of labour dystocia in this type of studies [13].

In conclusion, a combined intrapartum fetal monitoring with CTG and FPO could help to reduce Caesarean operations for non-reassuring CTG patterns without negatively affecting a neonatal outcome. Because of a low prevalence of a significant fetal acidosis in a general population, large multi-centre randomized trials would be needed to ascertain the benefit and safety of FPO in conjunction with CTG monitoring. 


\section{REFERENCES}

1. Perkins RP. Requiem for a heavyweight: the demise of scalp blood pH sampling. J Matern Fetal Med 1997; 6: 298.

2. Kühnert M, Seelbach-Gobel B, Butterwegge M. Predictive agreement between the fetal arterial oxygen saturation and fetal scalp pH: results of the German multicenter study. Am J Obstet Gynecol 1998; 178: 330-335.

3. East CE, Colditz PB, Begg LM, Brennecke SP. Update on intrapartum fetal pulse boximetry. Aust N Z J Obstet Gynaecol 2002; 42: 23-28.

4. Carter AM, Stiller R, Konig V, Jorgensen JS, Svendsen P, Huch R. Calibration of a reflectance pulse oximeter in fetal lambs for arterial oxygen saturations below 70\%. J Soc Gynecol Investig 1998; 5:255-259.

5. Dildy GA, Thorp J, Yeast J, Clark S. The relationship between oxygen saturation and pH in umbilical blood: Implications for intrapartum fetal oxygen saturation monitoring. Am J Obstet Gynecol 1996; 175: 682-687.

6. Kühnert M, Seelbach-Gobel B, Butterwegge M. Kritische Evaluierung der fetalen Pulsoximetrie im klinischen Einsatz. Geburtsh Frauenheilkd 2001; 61: 290-296.

7. Leszczynska-Gorzelak B, Poniedzialek-Czajkowska E, Oleszczuk J. Intrapartum cardiotocography and fetal pulse oximetry in assessing fetal hypoxia. Int $J$ Gynecol Obstet 2002; 76: 9-14.

8. Garite TJ, Dildy GA, McNamara H, Nageotte MP, Boehm FH, Dellinger EH, et al. A multicenter controlled trial of fetal pulse oximetry in the intrapartum management of nonreassuring fetal heart rate patterns. Am J Obstet Gynecol 2000; 183: 1049-1058.

9. Stiller R, von Mering R, König V, et al. How well does reflectance pulse oximetry reflect intrapartum fetal acidosis? Am J Obstet Gynecol 2002; 186: 1351-1357.

10. Alshimmiri M, Bocking AD, Gagnon R, Natale R, et al. Prediction of umbilical artery base excess by intrapartum fetal oxygen saturation monitoring. Am J Obstet Gynecol 1997; 177: 775-779.

11. Schmidt S, Koslowski S, Sierra F, et al. Clinical usefulness of pulse oximetry in the fetus with non-reassuring heart rate pattern. J Perinatol Med 2000; 28: 298-305.

12. Kühnert M, Schmidt S. Intrapartum management of nonreassuring fetal heart rate patterns: A randomized controlled trial of fetal pulse oximetry. Am J Obstet Gynecol 2004; 191: 1989-95.

13. Porreco RP, Boehm F, Dildy G, Hugh SM, Wickstrom EA, Garite TJ, et al. Dystocia in nulliparous patients monitored with fetal pulse oximetry. Am J Obstet Gynecol 2004; 190: 113-7.

\section{Acknowledgements}

This work was supported by the project „Increasing opportunities for career growth in research and development in the field of medical sciences“, ITMS 26110230067, co-funded by the EU and the European Social Fund, and the financial grant of the Slovak Research and Development Agency under the contract No. APVT-20-033104.

Received: Sept. 19, 2013

Accepted: October, 1, 2013 